\title{
Determination of members of a Borrelia afzelii- related group isolated from Ixodes nipponensis in Korea as Borrelia valaisiana
}

\author{
Toshiyuki Masuzawa, ${ }^{1}$ Takako Fukui, ${ }^{1}$ Masaki Miyake, ${ }^{1}$ Hee-Bok Oh, ${ }^{2}$ \\ Min-Kee Cho, ${ }^{3}$ Woo-Hyun Chang, ${ }^{3}$ Yasuyuki Imai ${ }^{1}$ \\ and Yasutake Yanagihara' ${ }^{1} \dagger$
}
1 Department of Microbiology, School of Pharmaceutical Sciences, University of Shizuoka, Shizuoka, Japan
2 Department of Microbiology, National Institute of Health, Seoul, Korea
3 Department of Microbiology, College of Medicine, Hallym University, Chunchon, Korea

\author{
Author for correspondence: Toshiyuki Masuzawa. Tel: +8154264 5710. Fax: +81542645715 \\ e-mail:masuzawa@u-shizuoka-ken.ac.jp
}

\begin{abstract}
The 165 rRNA sequences of the Korean Borrelia strains 5MT and 9MT, isolated from Ixodes nipponensis, showed identities of 99.0-99.1\% to that of $B$. afzelii. The strains were tentatively classified as belonging to the $B$. afzelii-related group. In this study, Korean isolates, including these strains, were characterized further and compared with recently described new species. These strains generated a RFLP pattern that has not been found previously in RFLP analysis of the 5S-235 rRNA intergenic spacer and the flagellin gene. When phylogenetic trees were constructed, based on the 5S-23S rRNA intergenic spacer, flagellin gene and 165 rRNA sequences, these Korean isolates formed a cluster with the Borrelia strain Am501 isolated from Ixodes columnae in Japan and Borrelia valaisiana strains VS116 and UK isolated from Ixodes ricinus in Europe and were distinguishable from the other species. However, these three groups of strains were divergent from each other in the molecular masses of the putative outer surface protein A (OspA) and in the sequences of the ospA gene. These findings suggest that these Korean isolates and one Japanese isolate are members of $B$. valaisiana and that OspA of this species is divergent, as is that of Borrelia garinii. This led to the speculation that $B$. valaisiana strains are adapted to the vector ticks found in each locality.
\end{abstract}

Keywords: Borrelia valaisiana, Lyme disease, Ixodes nipponensis, 16S rRNA, Korea

\section{INTRODUCTION}

Lyme borreliosis is the most prevalent tick-borne zoonotic disease (Steere, 1989) in Europe, North America and Far Eastern countries such as Japan, Russia and China (Anderson, 1989). The causative agent, Borrelia burgdorferi sensu lato, is classified into 10 species: B. burgdorferi sensu stricto (Burgdorfer et al., 1982; Johnson et al., 1984), isolated in North America and Europe; Borrelia garinii (Baranton et al., 1992) and Borrelia af zelii (Canica et al., 1993), isolated in Europe and east Asian countries; Borrelia japonica,

\footnotetext{
†Present address: Department of Medical Microbiology, College of Public Health, University of the Philippines Manila, 625 Pedro Gil Street, Ermita, Manila 1000, The Philippines.

The GenBank/EMBLDDBJ accession numbers for the 16S rRNA, 5S-23S intergenic spacer, fla and ospA sequences reported in this paper are $A B 013913-A B 013917, A B 014677-A B 014679, A B 016974-A B 016979$ and $A B 017479$.
}

Borrelia tanukii and Borrelia turdi, isolated from Ixodes ovatus, Ixodes tanuki and Ixodes turdus, respectively, in Japan (Fukunaga et al., 1996b; Kawabata et al., 1993); Borrelia andersonii, isolated from Ixodes dentatus in North America (Marconi et al., 1995); Borrelia valaisiana (Wang et al., 1997), formerly genomic group VS116, and Borrelia lusitaniae (Le Flèche et al., 1997), formerly genomic group PotiB2, isolated in Europe; and 'Borrelia bissettii' (Postic et al., 1998), formerly genomic group DN127, isolated in North America.

In Korea, B. burgdorferi sensu lato has been isolated from species of tick (Ixodes granulatus, Ixodes nipponensis and Ixodes persulcatus) and wild rodent (Apodemus agrarius). However, no cases of Lyme disease have been documented in Korea. These isolates were identified as $B$. garinii or $B$. afzelii by the ribotyping method, 16S rRNA-PCR (Park et al., 1993), reactivity with specific mAbs and 16S rRNA sequencing (Kee 
et al., 1994, 1996). Interestingly, some isolates from $I$. nipponensis were relatively similar, but not identical, to $B$. afzelii and were tentatively classified as belonging to the B. afzelii-related group (Kee et al., 1996). On the other hand, no isolates have been found from $I$. nipponensis in Japan.

In this study, Korean isolates tentatively classified as belonging to the $B$. af zelii-related genomic group were further characterized on the basis of sequencing of $16 \mathrm{~S}$ rRNA, the 5S-23S rRNA intergenic spacer, the flagellin gene and the outer surface protein A (OspA) gene and compared with recently described new species.

\section{METHODS}

Borrelia isolates. Eight Korean isolates, 5MT, 9MT and 10MT isolated from $I$. nipponensis, $5 \mathrm{Y}, 17 \mathrm{Y}$ and $18 \mathrm{Y}$ from $I$. granulatus, 935T from $I$. persulcatus and 934U from $A$. agrarius collected in Korea (Kee et al., 1994, 1996), were cultivated at $30^{\circ} \mathrm{C}$ in Barbour-Stoenner-Kelly II medium (Barbour, 1984). The standard strains listed in Table 1 were used for comparison of genetic characteristics.

PCR and RFLP analysis of the 5S-235 rRNA intergenic spacer and the flagellin gene. Primers corresponding to the $3^{\prime}$ end of the 5S rRNA $(r r f)\left(5^{\prime}\right.$ CTGCGAGTTCGCGGGAGA $\left.3^{\prime}\right)$, the $5^{\prime}$ end of the 23S rRNA $(r r l)\left(5^{\prime}\right.$ TCCTAGGCATTCACCATA $\left.3^{\prime}\right)$, the $5^{\prime}$ end of the flagellin gene (5' GCAGTTCAATCAGGTAACGG $3^{\prime}$ ) and $3^{\prime}$ end of the flagellin gene (5' AGGTTTTCAATAGCATACTC 3'), described previously (Fukunaga et al., 1996c; Masuzawa et al., 1996a; Postic et al., 1994), were synthesized by a custom oligonucleotide synthesis service (Bex Co., Tokyo, Japan). Aliquots $(2 \mathrm{ml})$ of cultures were washed and the cells were resuspended in $100 \mu \mathrm{l}$ water. The resultant cell suspensions were boiled at $100^{\circ} \mathrm{C}$ for $10 \mathrm{~min}$. PCR was performed by the method described previously (Fukunaga et al., 1996c; Postic et al., 1994). The amplification products of the $5 \mathrm{~S}-23 \mathrm{~S}$ rRNA PCR were digested with $M s e I$ and $D r a$ I and the digested DNA was electrophoresed through $16 \%$ polyacrylamide gels. The amplified DNA from the flagellin gene was digested with Bpu1102I, HhaI, HincII or DdeI and subsequently electrophoresed in $12 \%$ polyacrylamide gels. DNA fragments of pBR322 digested with $M s p I$, ranging from 26 to $622 \mathrm{bp}$, were electrophoresed as molecular size markers. DNA bands were visualized by ethidium bromide staining.

Sequencing of 16S rRNA, the 5S-23S rRNA intergenic spacer and the flagellin and ospA genes. The $\operatorname{ssp} A$ gene was amplified with primers A8 (5' CAATTTTCTATTTGTTATTTGTTAATC $3^{\prime}$ ), corresponding to the $5^{\prime}$ end of $\operatorname{ssp} A$, and BR1 ( $5^{\prime}$ TGACTCAGCACCTTTTTGTGC $\left.3^{\prime}\right)$, corresponding to the $5^{\prime}$ end of $\operatorname{ssp} B$, or BR2 (5' AAATCCTAGTAAATATTGTTT $3^{\prime}$ ), corresponding to the $5^{\prime}$ end of $o s p B$. The 16S rRNA sequences and flagellin $(f l a)$ gene were amplified with primer pairs $16 \mathrm{SF} 1$ (5' ATAACGAAGAGTTTGATCCTGGC $3^{\prime}$ ), corresponding to the $5^{\prime}$ end of $16 \mathrm{~S}$ rRNA, and 16SR (5' CAGCCGCACTTTCCAGTACG 3'), corresponding to the $3^{\prime}$ end of $16 \mathrm{~S}$ rRNA, and flaF $\left(5^{\prime}\right.$ GATTATAAATCATAATAGGTCAGC $3^{\prime}$ ), corresponding to the $5^{\prime}$ end of $f a$, and flaR2 (5' CTCCTCAATAAGCCTGCATTATGC $3^{\prime}$ ), corresponding to the $3^{\prime}$ end of $f l a$. The amplicons of the $\operatorname{ssp} A$ gene (about $980 \mathrm{bp}$ ), flagellin gene (about $970 \mathrm{bp}$ ), 16S rRNA (about $1350 \mathrm{bp}$ ) and the intergenic spacer sequence (about $250 \mathrm{bp}$ ) were cloned into the pGEM-T vector and the recombinant plasmids were transformed into Escherichia coli JM109 using the pGEM-T

Table 1. RFLP analysis of the 5S-23S rRNA intergenic spacer and flagellin gene

Taxa are listed as reported previously or as identified in this study. Exact restriction fragment sizes were determined from sequences. NA, Sequence not available; NS, no site; NT, not tested.

\begin{tabular}{|c|c|c|c|c|c|c|c|c|c|c|}
\hline \multirow[t]{3}{*}{ Taxon } & \multirow[t]{3}{*}{ Strain } & \multirow[t]{3}{*}{ Isolated from } & \multicolumn{3}{|c|}{ 5S-23S rRNA intergenic spacer } & \multicolumn{5}{|c|}{ Flagellin gene } \\
\hline & & & \multirow{2}{*}{$\begin{array}{c}\text { Amplicon } \\
\text { (bp) }\end{array}$} & \multicolumn{2}{|c|}{ Restriction fragments (bp) } & \multirow{2}{*}{$\begin{array}{c}\text { Amplicon } \\
\text { (bp) }\end{array}$} & \multicolumn{4}{|c|}{ Restriction fragments (bp) } \\
\hline & & & & DraI & MseI & & Bpu1102I & DdeI & HhaI & HincII \\
\hline B. garinii & $935 \mathrm{~T}$ & I. persulcatus & 237 & 185,52 & $107,79,51$ & 584 & Ns & $329,153,72,21,9$ & 405,179 & 453,131 \\
\hline B. afzelii & $934 \mathrm{U}$ & A. agraritus & 246 & $174,52,20$ & $107,68,51,20$ & NT & NT & NT & $\mathrm{NT}$ & NT \\
\hline B. afzelii & $17 \mathrm{Y}$ & I. granulatus & 246 & $174,52,20$ & $107,68,51,20$ & NT & NT & NT & NT & NT \\
\hline B. afzelii & $5 \mathrm{Y}$ & I. granulatus & $\sim 250$ & Similar to $17 \mathrm{Y}$ & Similar to $17 Y$ & NT & NT & NT & NT & $\mathrm{NT}$ \\
\hline B. afzelii & $18 Y$ & I. granulatus & $\sim 250$ & Similar to $17 \mathrm{Y}$ & Similar to $17 \mathrm{Y}$ & NT & NT & NT & $\mathrm{NT}$ & NT \\
\hline B. valaisiana & $5 \mathrm{MT}$ & I. nipponensis & 254 & 173,81 & $107,59,43,24,22$ & 585 & NS & $252,188,90,33,22$ & Ns & NS \\
\hline B. valaisiana & $9 \mathrm{MT}$ & 1. nipponensis & $\sim 250$ & Similar to $5 \mathrm{MT}$ & Similar to SMT & $\sim 590$ & Ns & Similar to $5 \mathrm{MT}$ & NS & NS \\
\hline B. valaisiana & $10 \mathrm{MT}$ & I. nipponensis & 254 & 173,81 & $150,58,24,22$ & 585 & NS & $221,135,118,90,21$ & NS & NS \\
\hline B. burgdorferi & $\mathrm{B} 31^{\mathrm{r}}$ & I. scapularis & 254 & $144,53,29,28$ & $107,52,38,29,28$ & 584 & Ns & $338,225,21$ & NS & NS \\
\hline B. garinii & $20047^{T}$ & I. ricinus & 253 & 201,52 & $107,95,51$ & 584 & Ns & $329,153,72,21,9$ & 405,179 & 453,131 \\
\hline B. garinit & NT29 & I. persulcatus & 253 & $144,57,52$ & $107,57,51,38$ & $\mathrm{NA}$ & $\mathrm{NA}$ & $\mathrm{NA}$ & $\mathrm{NA}$ & $\mathrm{NA}$ \\
\hline B. garinii & ChYl3p & I. persulcatus & 237 & 185,52 & $107,79,51$ & $\mathrm{NA}$ & NA & $\mathrm{NA}$ & $\mathrm{NA}$ & $\mathrm{NA}$ \\
\hline B. afzelii & VS $461^{T}$ & I. ricinus & 246 & $174,52,20$ & $107,68,51,20$ & 584 & NS & $305,183,42,33,21$ & ns & Ns \\
\hline B. japonica & $\mathrm{HO} 14^{\mathrm{T}}$ & I. ovatus & 236 & $\mathrm{NS}$ & $107,78,51$ & 584 & NS & $305,225,33,21$ & 348,236 & Ns \\
\hline B. valaisiana & $\mathrm{VS} 116^{\mathrm{T}}$ & I. ricinus & 255 & 203,52 & $174,51,23,7$ & 584 & Ns & $\begin{array}{c}188,135,117,90,33 \\
21\end{array}$ & NS & NS \\
\hline B. valaisiana & Am501 & I. columnae & 248 & NS & $168,51,23,6$ & 584 & NS & $\begin{array}{c}188,135,117,90,33 \\
21\end{array}$ & Ns & NS \\
\hline B. Iusitaniae & PotiB2 ${ }^{\mathrm{T}}$ & I. ricinus & 257 & $145,83,29$ & $107,82,39,29$ & 584 & NS & $338,225,21$ & $393,179,12$ & 453,131 \\
\hline B. andersonii & 21123 & I. dentatus & 266 & NS & $119,67,52,28$ & 584 & NS & $238,225,100,21$ & NS & NS \\
\hline B. tanukii & Hk512 & I. tanukii & 245 & $173,52,20$ & $174,51,20$ & 584 & NS & $338,225,21$ & 328,256 & $\mathrm{NS}$ \\
\hline B. turdi & $\mathrm{Ya}_{501^{\mathrm{T}}}$ & 1. turdus & 248 & $144,81,23$ & $\begin{array}{c}107,51,38,21,16 \\
8,7\end{array}$ & 584 & NS & $225,221,117,2 \mathrm{i}$ & 405,179 & 453,131 \\
\hline 'B. bissettii' & $\mathrm{DN} 127^{\mathrm{T}}$ & I. neotomae & 257 & $144,53,33,27$ & $107,52,38,33,27$ & 584 & Ns & $221,153,117,72,21$ & 405,179 & NS \\
\hline
\end{tabular}


vector system (Promega) according to the manufacturer's instructions. The recombinant plasmids were extracted from E. coli cultures using a PERFECT prep plasmid DNA kit (5 prime-3 prime) and sequenced by the dideoxy chaintermination method using a Taq Dye-Deoxy Terminator cycle sequencing kit with primers M13 (-29) and M13 reverse and a model 373A DNA sequencer (Applied Biosystems) or Sequi Therm EXEL II Long-Read DNA Sequencing Kit LC (Epicentre Technology) and an LI-COR 4000 DNA sequencer. At least three clones were sequenced for determination of each strain.

Nucleotide sequence accession numbers. The sequences of the 5S-23S rRNA intergenic spacer, flagellin gene, 16S rRNA gene and $\operatorname{sp} A$ gene determined in this study have been submitted to the DDBJ, EMBL and GenBank databases under the accession numbers listed in the legends to Figs 1-3 and in Table 3.

Phylogenetic analysis. Sequences were aligned and a similarity matrix and neighbour-joining phylogenetic tree were constructed using the DNASTAR program.

SDS-PAGE and Western blotting. SDS-PAGE and Western blotting were carried out according to a previously described method (Masuzawa et al., 1991). Ten micrograms protein was applied to each lane of a $12.5 \%$ polyacrylamide gel. After electrophoresis, the gels were stained with Coomassie brilliant blue. Antigens were transferred to PVDF membranes (Bio-Rad) and specific antigen bands were subsequently detected by immunostaining with $\mathrm{mAbs}$ diluted $1: 50$ to $1: 100$. The mAbs used were: $\mathrm{H} 9724$ and O1441 b to flagellin; P31a, P31b, P31c and P31d to OspA (Masuzawa et al., 1996c); G7 to OspC (Masuzawa et al., 1996b); and O62a to heat-shock protein 60 (Hsp60, Masuzawa et al., 1996c).

\section{RESULTS AND DISCUSSION}

\section{Phylogenetic analysis of the $B$. afzelii-related group on the basis of 16S rRNA gene sequences}

A phylogenetic tree based on 16S rRNA gene sequences was constructed on the basis of a sequencesimilarity matrix of the $16 \mathrm{~S} \mathrm{rRNA}$ gene (1367 bp) (Fig. 1). The $16 \mathrm{~S}$ rRNA sequence of strain 10MT was determined in this study, while the other sequences were obtained from previous reports as described in the figure legend. The sequences of the three strains

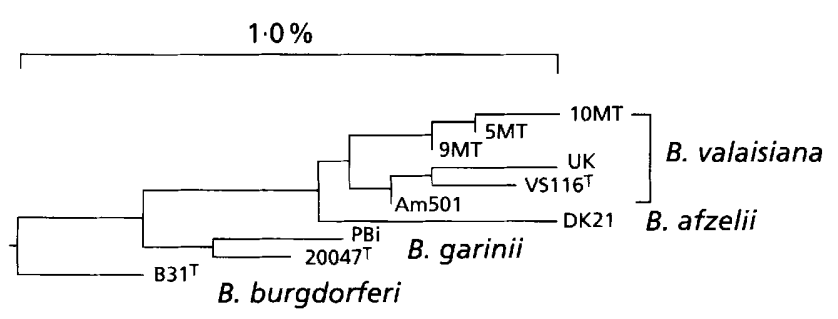

Fig. 1. Phylogenetic tree based on 165 rRNA sequences. The $16 \mathrm{~S}$ rRNA sequence of strain 10MT (accession no. AB016974) was determined in this study. Previously published sequences, deposited with the following accession numbers, were also utilized: 5MT (U44938), 9MT (L39080), VS116 ${ }^{\top}$ (X98232), UK (X98233), Am501 (D67021), B31 ${ }^{\top}$ (B59293), DK21 (X85191), $20047^{\top}$ (D67018) and PBi (X85199). Bar, sequence divergence of $1.0 \%$.

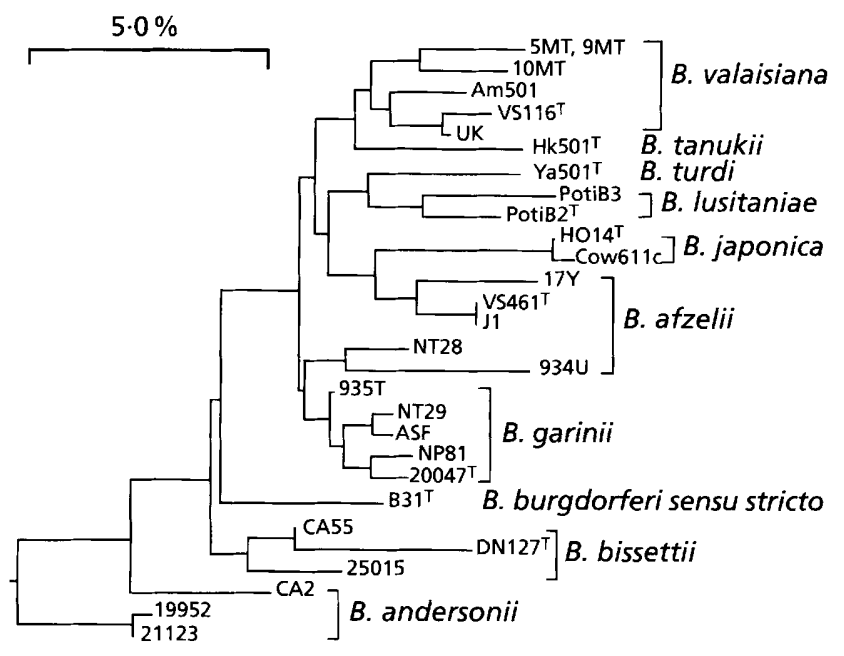

Fig. 2. Phylogenetic tree based on 5S-23S rRNA intergenic spacer sequences. Sequences of strains 17Y (accession no. AB013913), 5MT (AB013914), 10MT (AB013915), $934 \mathrm{U}$ (AB013917) and 935T (AB013916) were determined in this study. Previously published sequences, deposited with the following accession numbers, were also utilized: VS116 (L30134), UK (L30133), Am501 (D84402), B31 ${ }^{\top}$ (L30127), 20047 (L30119), NP81 (D84406), NT29 (L30130), ASF (D84403), ChY13p (AB003785), VS461 ${ }^{\top}$ (L30135), NT28 (D84405), HO14 ${ }^{\top}$ (L30128), 19952 (L30118), 21123 (L30120), CA2 (L30123), Hk501 ${ }^{\top}$ (D84404), $\mathrm{Ya501}^{\top}$ (D84407), PotiB2 $^{\top}$ (L30131), PotiB3 (L30132), DN127 (L30126), CA55 (L30124) and 25015 (L30122). Bar, sequence divergence of $5 \%$.

5MT, 9MT and 10MT clustered with those of strains VS $116^{\mathrm{T}}$ and UK of the recently described new species B. valaisiana and Borrelia sp. strain Am501, isolated from Ixodes columnae in Japan, and showed the highest identities, $99 \cdot 2-99.9 \%$, to these strains. Kee et al. (1996) tentatively classified these strains as belonging to the $B$. afzelii-related genomic group on the basis of $16 \mathrm{~S}$ rRNA gene sequences. However, the strains showed greater sequence identity to $B$. valaisiana than to $B$. afzelii. These observations strongly suggested that the Korean isolates from $I$. nipponensis, the European isolates from Ixodes ricinus and the Japanese isolates from I. columnae are closely related.

\section{RFLP analysis of the 5S-235 rRNA intergenic spacer and flagellin gene}

The results of RFLP analysis of the 5S-23S rRNA intergenic spacer sequence and flagellin gene are summarized in Table 1. Strains 5Y, 17Y, $18 \mathrm{Y}$ and 934U generated RFLP patterns for the 5S-23S rRNA intergenic spacer identical to that of $B$. afzelii strain VS461 ${ }^{\mathrm{T}}$. Strain $935 \mathrm{~T}$ generated a pattern identical to that of $B$. garinii strain ChY13p, isolated from $I$. persulcatus in northern China (Li et al., 1998), while strains 5MT, 9MT and 10MT, isolated from $I$. nipponensis, showed unique RFLP patterns that have not been reported previously. These three strains also generated unique patterns on RFLP analysis of the flagellin gene. 


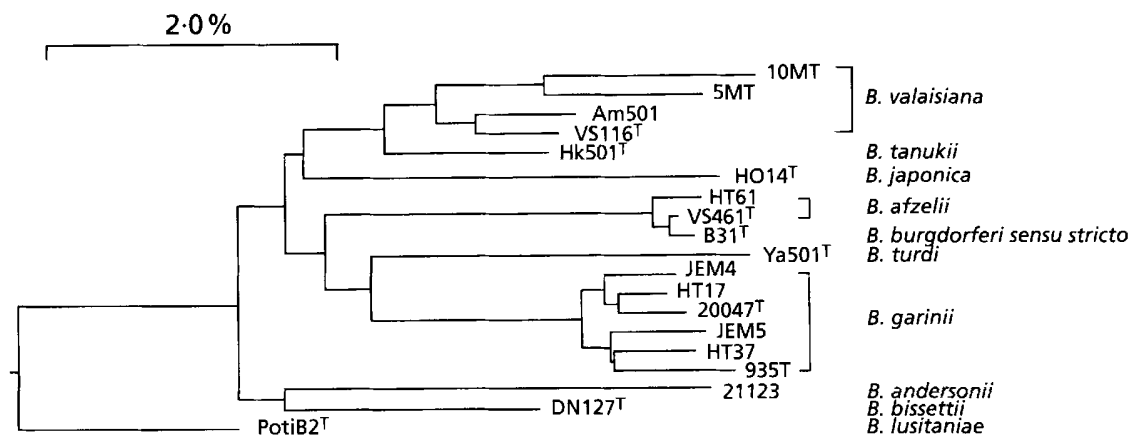

Fig. 3. Phylogenetic tree based on flagellin gene sequences. Sequences of strains 5MT (accession no. AB014677), 10MT (AB014678) and 935T (AB017479) were determined in this study. Previously published sequences, deposited with the following accession numbers, were also utilized: VS116 ${ }^{\top}$ (D82854), Am501 (D82855), B31 ${ }^{\top}$ (X15661), GeHo (X56334), $20047^{\top}$ (D82846), HT17 (D63363), HT19 (D63371), JEM4 (D63364), JEM5 (D63370), HT37 (D63369), VS461 ${ }^{\top}$ (D63365), HT61 (D63366), HO14 ${ }^{\top}$ (D82852), 21123 (D83764), Hk501 ${ }^{\top}$ (D82847), Ya501 ${ }^{\top}$ (D82849), PotiB2 ${ }^{\top}$ (D85856) and DN127 ${ }^{\top}$ (D82857). Bar, sequence divergence of $2 \%$.

\section{Phylogenetic analysis of the 5S-23S rRNA intergenic spacer and flagellin gene}

Figs 2 and 3 show the phylogenetic trees constructed on the basis of the $5 \mathrm{~S}-23 \mathrm{~S}$ rRNA intergenic spacer and flagellin gene sequences. 5S-23S rRNA intergenic spacer sequences of strains $17 \mathrm{Y}$ and $935 \mathrm{~T}$ showed greatest identities to $B$. afzelii strain VS461 ${ }^{\mathrm{T}}(99.6 \%)$ and $B$. garinii strain ChY13p $(95.4 \%)$, respectively. Furthermore, the sequences from strains 5MT and 10MT, which generated unique RFLP patterns, showed the greatest identity $(94.9-97.3 \%)$ to $B$. valaisiana strains VS116 $6^{\mathrm{T}}$ and UK, isolated from $I$. ricinus in Europe, and formed a cluster with these strains. Similar results were obtained from sequence analysis of the flagellin gene (Fig. 3). Sequences of strains 5MT and 10MT showed the greatest identity (about 97\%) to strain VS1 $16^{\mathrm{T}}$ but were also similar to strain Am501, isolated from I. columnae in Japan. The Korean strains formed a cluster with the Borrelia sp. strain Am501 and $B$. valaisiana strain VS1 $16^{\mathrm{T}}$ and were distinct from other strains. These facts indicate that the Korean strains and Am501 should be classified as B. valaisiana. The Korean isolates identified as $B$. valaisiana showed specific RFLP patterns for the 5S-23S rRNA intergenic spacer and flagellin gene sequences. These methods are useful for the identification of Borrelia species on the basis of DNA extracted from vector ticks and/or small amounts of culture material. From the results obtained, the methods could be applicable to an epidemiological survey in this area.

\section{Protein profiles and characterization of the ospA gene}

Strains 5MT and 10MT each contained a $32 \mathrm{kDa}$ protein that reacted with the anti-OspA mAb P31c (Fig. 4 and Table 2). Strain 9MT had a protein profile similar to those of strains 5MT and 10MT with respect to the molecular mass of OspA and other major

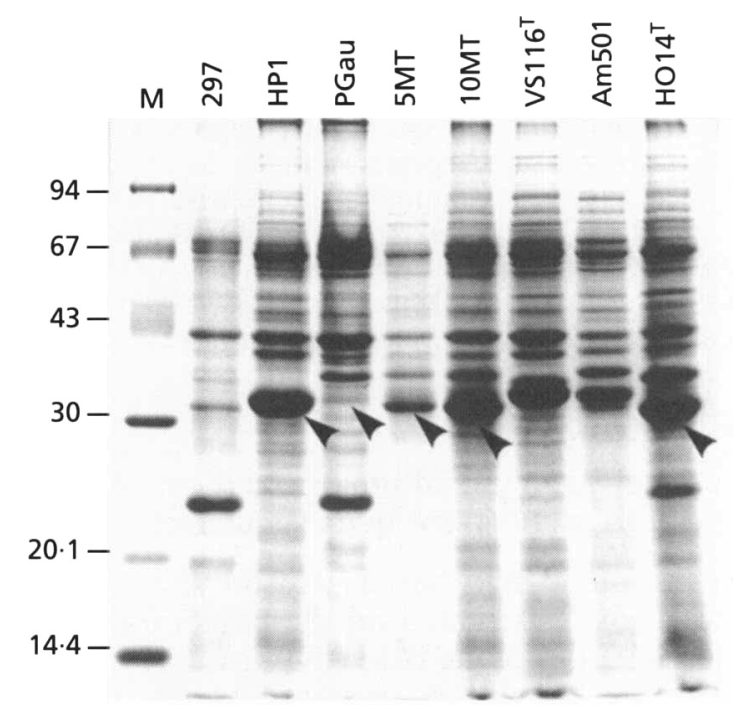

Fig. 4. SDS-PAGE profiles of Borrelia strains used in this study. Ten micrograms protein was applied to each lane of a $12.5 \%$ polyacrylamide gel. Arrowheads indicate the position of OspA reactive to mAb P31c. $M$, molecular mass markers.

proteins (data not shown), as previously reported (Kee et al., 1994). However, strains VS116 $6^{\mathrm{T}}$ and Am501 contained OspA proteins of different sizes and these did not react with $\mathrm{mAb}$ P31c. European strains classified as $B$. valaisiana express proteins that appear to be OspA, in the size range 32-35 kDa (Nohlmans et al., 1995; Péter \& Bretz, 1992; Wang et al., 1997). Specific mAbs are useful for the detection of specific Borrelia species in the tick midgut and identify them by immunological reactivity. However, in this study, we could not identify a mAb that reacted specifically with $B$. valaisiana among a battery of mAbs tested. Previously, Wang et al. (1997) also reported that the mAbs tested in their study were not reactive to $B$. 
Table 2. Reactivity of the isolates with various mAbs

The targets of the various mAbs tested are indicated in parentheses.

\begin{tabular}{|c|c|c|c|c|c|c|c|c|c|}
\hline Taxon & Strain & $\begin{array}{c}\text { 062a } \\
\text { (Hsp60) }\end{array}$ & $\begin{array}{c}\text { H9724 } \\
\text { (flagellin) }\end{array}$ & $\begin{array}{c}01441 b \\
\text { (flagellin) }\end{array}$ & $\begin{array}{c}\text { P31a } \\
\text { (OspA) }\end{array}$ & $\begin{array}{c}\text { P31b } \\
(\text { OspA })\end{array}$ & $\begin{array}{c}\text { P31c } \\
(\text { OspA) }\end{array}$ & $\begin{array}{c}\text { P31d } \\
(\text { OspA) }\end{array}$ & G7 (OspC) \\
\hline B. burgdorferi & 297 & + & + & - & - & - & - & - & + \\
\hline B. garinii & HP1 & + & + & - & - & + & + & - & + \\
\hline B. afzelii & PGau & + & + & - & - & - & + & + & + \\
\hline B. valaisiana & $5 \mathrm{MT}$ & + & + & - & - & - & + & - & + \\
\hline B. valaisiana & $10 \mathrm{MT}$ & + & + & - & - & - & + & - & + \\
\hline B. valaisiana & $\mathrm{VS} 116^{\mathrm{T}}$ & + & + & - & - & - & - & - & + \\
\hline B. valaisiana & Am501 & + & + & - & - & - & - & - & + \\
\hline B. japonica & $\mathrm{HO} 14^{\mathrm{T}}$ & + & + & + & - & - & + & - & + \\
\hline
\end{tabular}

Table 3. Sequence identity matrix of partial sequences $(819 \mathrm{bp})$ of ospA genes

The sequences shown were all determined in this study.

\begin{tabular}{|lccccccc|}
\hline Taxon & Strain & 5MT & 10MT & VS116 & Am501 & Ya501 $^{\text {T }}$ & Accession no. $^{\text {10MT }}$ \\
\hline B. valaisiana & 5MT & 100 & $99 \cdot 6$ & $87 \cdot 4$ & $93 \cdot 3$ & $98 \cdot 4$ & AB016977 \\
B. valaisiana & 10MT & & 100 & $87 \cdot 0$ & $92 \cdot 9$ & $98 \cdot 0$ & AB016978 \\
B. valaisiana & VS116 & & & 100 & $90 \cdot 8$ & $86 \cdot 5$ & AB016979 \\
B. valaisiana & Am501 & & & & 100 & $92 \cdot 4$ & AB016976 \\
B. turdi & Ya501 & & & & & 100 & AB016975 \\
\hline
\end{tabular}

valaisiana. Further study is necessary to identify a $\mathrm{mAb}$ that reacts specifically with this species.

In order to estimate the similarity among strains $5 \mathrm{MT}$, 10MT, Am501 and VS116 ${ }^{\mathrm{T}}$, ospA sequences were determined and compared with each other (Table 3 ). The greatest identity $(99.6 \%)$ was observed between strains 5MT and 10MT. Interestingly, relatively greater identity $(98 \cdot 0-98 \cdot 4 \%)$ was found to the osp $A$ sequence of $B$. turdi strain Ya501 ${ }^{\mathrm{T}}$, but sequences from strains Am501 and VS116 ${ }^{\mathrm{T}}$ were about 93 and $87 \%$ identical to those of strains $5 \mathrm{MT}$ and $10 \mathrm{MT}$, respectively. These results clearly indicate that the osp $A$ sequences of strains $5 \mathrm{MT}$ and 10MT were quite similar to one another and relatively divergent from those of strains Am501 and VS116 ${ }^{\mathrm{T}}$. Other strains belonging to $B$. valaisiana could not be examined in this study as $o s p A$ sequences are not yet available for these strains. Based on the currently available information, osp $A$ sequences from European and Korean strains and Japanese strain Am501, which are classified as $B$. valaisiana, are heterogeneous, like that of $B$. garinii.

The three Korean strains were isolated from I. nipponensis collected in Haenam, located at the southern tip of the Korean peninsula (Kee et al., 1994, 1996). We performed a survey in Choongju, located in the central part of Korea, in 1997 and isolated typical B. garinit and $B$. afzelii strains from $I$. nipponensis collected around this area, but did not obtain strains similar to $B$. valaisiana (unpublished results).
The geographical distribution of $\boldsymbol{B}$. valaisiana is still unclear. Strains have been isolated and/or specific DNA has been detected from $I$. ricinus collected in the Netherlands (Rijpkema et al., 1995), Switzerland (Filipuzzi-Jenny et al., 1993; Péter \& Bretz, 1992), the United Kingdom (Livesley et al., 1995), Italy (Cinco et al., 1998), Croatia (Golubic et al., 1998; Rijpkema et al., 1996) and Ireland (Kirstein et al., 1997). A species of Borrelia was also isolated from I. persulcatus in the central Urals (Lesnki et al., 1997). These reports suggest that $B$. valaisiana is distributed in various European countries and central Eurasia. Also, strain Am501, isolated from I. columnae in Japan, has been identified as B. valaisiana on the basis of flagellin (Fukunaga \& Koreki, 1996; Fukunaga et al., 1996c) and 16S rRNA gene sequences (Fukunaga et al., 1996b; Le Flèche et al., 1997; Wang et al., 1997). Recent taxonomic characterization of Borrelia has indicated that the ticks I. ovatus, I. turdus and I. tanuki transmit $B$. japonica, B. turdi and $B$. tanukii, respectively (Fukunaga et al., 1996a; Kawabata et al., 1993; Nakao \& Miyamoto, 1993). In contrast, I. ricinus ticks can transmit five species of Borrelia, $B$. burgdorferi sensu stricto, B. garinii, B. afzelii, B. valaisiana and $B$. lusitaniae (Baranton et al., 1992; Canica et al., 1993; Le Flèche et al., 1997; Postic et al., 1994; Wang et al., 1997). Also, I. persulcatus carries B. garinii, B. afzelii and possibly $B$. valaisiana but not $B$. burgdorferi sensu stricto (Li et al., 1998; Masuzawa et al., 1997; Postic et al., 1997; Sato et al., 1996). Marti Ras et al. (1997) 
proposed that European $B$. burgdorferi sensu stricto strains may have been imported recently from North America and have begun to evolve and diverge in Europe. The American ancestor of $B$. burgdorferi has probably evolved to $B$. burgdorferi sensu stricto, $B$. andersonii and ' $B$. bissettii', each adapted to their own vector tick species in North America. These observations lead us to speculate that the Korean Borrelia strains (5MT, 9MT and 10MT) and the Japanese isolate strain Am501, as members of B. valaisiana, are adapted to the ticks, $I$. nipponensis and $I$. columnae, that are found in their respective localities and are differentiated into these borrelia groups by $\operatorname{osp} A$ gene sequences and their products.

\section{ACKNOWLEDGEMENTS}

We thank Dr G. Baranton, Pasteur Institute, Paris, and Dr M. Nakao, Asahikawa Medical College, Japan, for providing Borrelia strains. This study was supported in part by Grants-in-Aid for International Cooperative Research (nos 08044310, 08041181 and 10041204) and Grants-in-Aid for Scientific Research (nos 07670320, 08670312 and 09670294) from the Ministry of Education, Science and Culture of Japan

\section{REFERENCES}

Anderson, J. F. (1989). Epizootiology of Borrelia in Ixodes tick vectors and rescrvoir hosts. Rev Infect Dis 11 (Suppl. 6), SI451-S1459.

Baranton, G., Postic, D., Saint Girons, I., Boerlin, P., Piffaretti, J.-C., Assous, M. \& Grimont, P. A. D. (1992). Delineation of Borrelia burgdorferi sensu stricto, Borrelia garinii sp. nov., and group VS461 associatcd with Lyme borreliosis. Int $J$ Syst Bacteriol 42, 378-383.

Barbour, A. G. (1984). Isolation and cultivation of Lyme disease spirochetes. Yale I Biol Med 57, 521-525.

Burgdorfer, W., Barbour, A. G., Hayes, S. F., Benach, J. L., Grunwaldt, E. \& Davis, J. P. (1982). Lyme disease - a tick-borne spirochetosis? Science 216, 1317-1319.

Canica, M. M., Nato, F., du Merle, L., Mazie, J. C., Baranton, G. \& Postic, D. (1993). Monoclonal antibodies for identification of Borrelia afzelii sp. nov. associated with late cutaneous manifestations of Lyme borreliosis. Scand J Infect Dis 25, 441-448.

Cinco, M., Padovan, D., Murgia, R., Poldini, L., Frusteri, L., van de Pol, I., Verbeek-De Kruif, N., Rijpkema, S. \& Maroli, M. (1998). Rate of infection of Ixodes ricinus ticks with Borrelia burgdorferi sensu stricto, Borrelia garinii, Borrelia afzelii and group VS116 in an endemic focus of Lyme disease in Italy. Eur $J$ Clin Microbiol Infect Dis 17, 90-94.

Filipuzzi-Jenny, E., Blot, M., Schmid-Berger, N., Meister-Turner, J. \& Meyer, J. (1993). Genctic diversity among Borrelia burgdorferi isolates: more than threc genospecies? Res Microbiol 144, 295-304

Fukunaga, M. \& Koreki, Y. (1996). A phylogenetic analysis of Borrelia burgdorferi sensu lato isolates associated with Lyme disease in Japan by flagellin gene sequence determination. Int $J$ Syst Bacteriol 46, 416-421.

Fukunaga, M., Hamase, A., Okada, K., Inoue, H., Tsuruta, Y., Miyamoto, K. \& Nakao, M. (1996a). Characterization of spirochetes isolated from ticks (Ixodes tanuki, Ixodes turdus, and
Ixod's (columae) and comparison of the sequences with those of Borrelia burgdorferi sensu lato strains. Appl Environ Microbiol 62, 2338-2344.

Fukunaga, M., Hamase, A., Okada, K. \& Nakao, M. (1996b). Borrelia tanukii sp. nov, and Borrelia turdae sp. nov. found from ixodid ticks in Japan : rapid species identification by $16 \mathrm{~S}$ rRNA gene-targeted PCR analysis. Microbiol Immunol 40, 877-881.

Fukunaga, M., Okada, K., Nakao, M., Konishi, T. \& Sato, Y. (1996c). Phylogenetic analysis of Borrelia species based on flagellin gene sequences and its application for molecular typing of Lyme disease borreliae. Int J Syst Bacteriol 46, 898-905.

Golubic, D., Rijpkema, S., Tkalec-Makovec, N. \& Ruzic, E. (1998). Epidemiologic, ecologic and clinical characteristics of Lymc borrcliosis in northwest Croatia. Acta Med Croatica 52, 7-13.

Johnson, R. C., Schmid, G. P., Hyde, F. W., Steigerwalt, A. G. \& Brenner, D. J. (1984). Borrelia burgdorferi sp. nov.: etiologic agent of Lyme disease. Int $J$ Syst Bacteriol 34, 496-497.

Kawabata, H., Masuzawa, T. \& Yanagihara, Y. (1993). Genomic analysis of Borrelia japonica sp. nov. isolated from Ixodes ovatus in Japan. Microbiol Immunol 37, 843 848.

Kee, S. H., Hwang, K. J., Oh, H. B. \& Park, K. S. (1994). Identification of Borrelia burgdorferi isolated in Korea using outer surface protein A (OspA) scrotyping system. Microbiol Immunol 38, 989-993.

Kee, S. H., Yoon, J. H., Oh, H. B., Park, Y. H., Kim, Y. W., Cho, M. K., Park, K. S. \& Chang, W. H. (1996). Genetic analysis of Borrelia burgdorferi sensu lato in Korea using genomic hybridization and $16 \mathrm{~S}$ rRN $\Lambda$ gene sequence determination. Microbiol Immunol 40, 599-605.

Kirstein, F., Rijpkema, S., Molkenboer, M. \& Gray, J. S. (1997). The distribution and prevalence of $B$. burgdorferi genomospecies in Ixodes ricinus ticks in Ireland. Eur J Epidemiol 13, 67-72.

Le Flèche, A., Postic, D., Girardet, K., Péter, O. \& Baranton, G. (1997). Characterization of Borrelia lusitaniae sp. nov. by $16 \mathrm{~S}$ ribosomal DNA sequence analysis. Int $J$ Syst Bacteriol 47, $921-925$.

Lesnki, O. M., Istomina, O. I., Rijpkema, S., Bruininck, H. \& Beliaeva, M. L. (1997). The clinical manifestations of Lyme borreliosis in the Middle Urals and their association with Borrelia burgdorferi genospecies. Ter Arkh 69, 9-12.

Li, M., Masuzawa, T., Takada, N. \& 7 other authors (1998). Lyme disease Borrelia species in northeastern China resemble those isolated from far eastern Russia and Japan. Appl Environ Microbiol 64, 2705-2709.

Livesley, M. A., Thompson, I. P., Rainey, P. B. \& Nuttall, P. A. (1995). Comparison of Borrelia isolated from UK foci of Lyme disease. FEMS Microbiol Lett 130, 151-157.

Marconi, R. T., Liveris, D. \& Schwartz, I. (1995). Identification of novel insertion elements, restriction fragment length polymorphism patterns, and discontinuous $23 \mathrm{~S}$ rRNA in Lyme disease spirochetes: phylogenetic analysis of rRNA genes and their intergenic spacers in Borrelia japonica sp. nov. and genomic group 21038 (Borrelia andersonii sp. nov.) isolates. $J$ Clin Microbiol 33, 2427-2434.

Marti Ras, N., Postic, D., Foretz, M. \& Baranton, G. (1997). Borrelia burgdorferi sensu stricto, a bacterial species 'Made in the U. S. A.'? Int J Syst Bacteriol 47, 1112-1117.

Masuzawa, T., Okada, Y., Yanagihara, Y. \& Sato, N. (1991). Antigenic properties of Borrelia burgdorferi isolated from Ixodes ovatus and Ixodes persulcatus in Hokkaido, Japan. JClin Microbiol 29, 1568-1573.

Masuzawa, T., Komikado, T., Iwaki, A., Suzuki, H., Kaneda, K. \& 
Yanagihara, Y. (1996a). Characterization of Borrelia sp. isolated from Ixodes tanuki, I. turdus, and I. columnae in Japan by restriction fragment length polymorphism of $r r f(5 \mathrm{~S})-r r l$ (23S) intergenic spacer amplicons. FEMS Microbiol Lett 142, 77-83.

Masuzawa, T., Suzuki, H., Kawabata, H., Ishiguro, F., Takada, N. \& Yanagihara, Y. (1996b). Characterization of Borrelia spp. isolated from the tick, Ixodes tanuki and small rodents in Japan. $J$ Wildl Dis 32, 565-571.

Masuzawa, T., Wilske, B., Komikado, T. \& 9 other authors (1996c). Comparison of OspA serotypes for Borrelia burgdorferi sensu lato from Japan, Europe and North America. Microbiol Immunol 40, 539-545.

Masuzawa, T., Iwaki, A., Sato, Y., Miyamoto, K., Korenberg, E. I. \& Yanagihara, Y. (1997). Genetic diversity of Borrelia burgdorferi sensu lato isolated in far eastern Russia. Microbiol Immunol 41, $595-600$

Nakao, M. \& Miyamoto, K. (1993). Isolation of spirochetes from Japanese ixodid ticks, Ixodes tanuki, Ixodes turdus, and Ixodes columnae. Jpn J Sanit Zool 44, 49-52.

Nohlmans, L. M. K. E., de Boer, R., van den Bogaard, A. E. J. M. \& van Boven, C. P. A. (1995). Genotypic and phenotypic analysis of Borrelia burgdorferi isolates from The Netherlands. J Clin Microbiol 33, 119-125.

Park, K. H., Chang, W. H. \& Schwan, T. G. (1993). Identification and characterization of Lyme disease spirochetes, Borrelia burgdorferi sensu lato, isolated in Korea. J Clin Microbiol 31, 1831-1837.

Péter, O. \& Bretz, A. G. (1992). Polymorphism of outer surface proteins of Borrelia burgdorferi as a tool for classification. Int $J$ Med Microbiol Virol Parasitol Infect Dis 277, 28-33.

Postic, D., Assous, M. V., Grimont, P. A. D. \& Baranton, G. (1994). Diversity of Borrelia burgdorferi sensu lato evidenced by restriction fragment length polymorphism of $r f(5 \mathrm{~S})$-rrl (23S) intergenic spacer amplicons. Int J Syst Bacteriol 44, 743-752.

Postic, D., Korenberg, E., Gorelova, N., Kovalevski, Y. V., Bellenger, E. \& Baranton, G. (1997). Borrelia burgdorferi sensu lato in Russia and neighbouring countries: high incidence of mixed isolates. Res Microbiol 148, 691-702.

Postic, D., Marti Ras, N., Lane, R. S., Hendson, M. \& Baranton, G. (1998). Expanded diversity among Californian borrelia isolates and description of Borrelia bissettii sp. nov. (formerly Borrelia group DN127). J Clin Microbiol 36, 3497-3504.

Rijpkema, S. G. T., Molkenboer, M. J. C. H., Schouls, L. M., Jongejan, F. \& Schellekens, J. F. P. (1995). Simultaneous detection and genotyping of three genomic groups of Borrelia burgdorferi sensu lato in Dutch Ixodes ricinus ticks by characterization of the amplified intergenic spacer region between $5 \mathrm{~S}$ and $23 \mathrm{~S}$ rRNA genes. $J$ Clin Microbiol 33, 3091-3095.

Rijpkema, S., Golubic, D., Molkenboer, M., Verbeek-De Kruif, N. \& Schellekens, J. (1996). Identification of four genomic groups of Borrelia burgdorferi sensu lato in Ixodes ricinus ticks collected in a Lyme borreliosis endemic region of northern Croatia. Exp Appl Acarol 20, 23-30.

Sato, Y., Miyamoto, K., Iwaki, A. \& 7 other authors (1996). Prevalence of the Lyme disease spirochetes in Ixodes persulcatus and wild rodents in far eastern Russia. Appl Environ Microbiol 62, 3887-3889.

Steere, A. C. (1989). Lyme disease. New Engl J Med 321, 586-596.

Wang, G., van Dam, A. P., Le Flèche, A., Postic, D., Péter, O., Baranton, G., de Boer, R., Spanjaard, L. \& Dankert, J. (1997). Genetic and phenotypic analysis of Borrelia valaisiana sp. nov. (Borrelia genomic groups VS116 and M19). Int J Syst Bacteriol 47, 926-932 